\title{
Are Value At Risk And Maximum Drawdown Different From Volatility In Stock Market?
}

Soo-Hyun Kim, Soongsil University, South Korea

\begin{abstract}
Measuring risk is the key component in many asset pricing models. Although volatility is the most widely used measure for the risk, Value at Risk (VaR) and Maximum drawdown (MDD) are also considered as alternative risk measure. This article questions whether VaR and MDD contain additional information to volatility in equity market. The empirical analysis is conducted using the stocks listed in Korean stock market. By constructing portfolios in accordance with three risk measures, cross-sectional predictability is tested. The primary findings are as follow; (1) the return patterns are bell shaped in all measures and (2) VaR and MDD do not capture additional risk factors after conditioning volatility.
\end{abstract}

Keywords: Value at Risk; Maximum Drawdown; Risk Management

\section{INTRODUCTION}

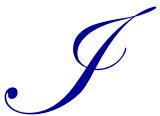

$\mathrm{n}$ modern finance, expected return and risk are the key components both in theory and practice. For measuring risk, volatility, the standard deviation of asset return, has been considered the most popular measure. Most of asset pricing models such as CAPM, GARCH, and Black-Scholes formula all incorporate volatility as the risk factor. In empirical asset pricing models, volatility is carefully studied in line with return predictability. For instance, Ang, Hodrick, Xing \& Xhang $(2006,2009)$ report the structure of stock volatility and its return predictability. They document that high volatility predicts low future return in U.S. and international stock market. The other example among many others is the work by Adrian and Rosenberg (2008), where they argue that short term volatility and long term volatility play different roles in market risk. Naturally, practitioners in asset management industry deal with volatility as the main measure of the risk in the investment activity.

Although volatility has strong theoretical support, it has a few drawbacks. Most of the arguments are related to the probability density of asset returns. Various researchers shed light on this issue, and develop alternative measures such as time-varying volatility, structural volatility and so on (see Duffie \& Jun, 1997). On the other hand, asset management practitioners focus on symmetric nature of volatility. Volatility or standard deviation of the return equally weighs both on upside and downside deviation from the average. However, in many cases investors care much more on the downside. Obviously, this argument is also associated with the probability structure of the returns. Asset managers have used value-at-risk (VaR) and maximum drawdown (MDD) as their alternative risk measures in the hope that they capture downside risks. At least in Korean asset management industry, a typical investment prospectus and investment report include realized return, volatility, Sharpe Ratio, VaR, and/or MDD.

VaR has long history being studied in the context of financial market. Many researchers apply the method in various financial markets. Giot and Laurent (2003) analyze market risk in commodity, and Kang and Yoon (2007) examine individual stock returns in Korean market. There are many other papers that utilize VaR approach in various securities markets such as the work by Huang and Lin (2004) for equity index futures or the one by Wu and Shieh (2007) for interest rate futures. In case of MDD, most research focuses on the mathematical properties of stochastic processes of asset return (Douady, Shiraev \& Yor 2000; Magdon-Ismail, Atiya, Pratap \& Abu-Mostafa 2004) or microeconomic utility research (Kim, 2011). For empirical study, Kim \& Lee (2011) recently report the comparative analysis between MDD and Calmar ratio in various equity indices. 
The research question is grown out of the practice of Korean asset management. Managers seem to believe that VaR and MDD have additional information to volatility. This article tries to test whether VaR and MDD contain different risk component from volatility in Korean stock market. In order to see this, we compare the performances of portfolios which are constructed based on three risk measures. By grouping stocks based on past risk level, five portfolios are constructed and various statistics of the portfolio performances are investigated. I find that portfolios on VaR and MDD also have the similar risk-return profiles as those on volatility. The return average increases from low risk to mid risk level and decreases from mid to high level. The risks all go up along with the past risk level in three measures. Two-way analyses are also conducted, where portfolios are constructed by both volatility and VaR (and MDD) at the same time. The purpose of this experiment is to study the effect of VaR and MDD after conditioning volatility level. In this analysis, no significant evidence is found that VaR and MDD capture additional risk other than volatility.

This paper proceeds as follows. In methodology section, VaR and MDD are briefly reviewed and the data and empirical methodologies are explained. In the next section, the empirical results are discussed followed by the conclusion.

\section{METHODOLOGIES}

\section{VaR and MDD}

Under normality assumption on asset return, $\mathrm{VaR}$ is defined as in equation (1).

$$
\operatorname{VaR}=z_{\alpha} \sigma_{r}
$$

The variable $z_{\alpha}$ is the value for significance level $\alpha$ under standard normal distribution and $\sigma_{r}$ is the standard deviation for asset return. There have been proposed many alternative measures for VaR because normality of asset returns might not be guaranteed. Asset returns are known as fat-tail and/or skewed distribution. Apart from many parametric alternative VaR approach, this paper chooses historical VaR for the analysis. The reasons are as follows. First, the purpose of the paper is to compare the effects of three risk measures. VaR captures the worst $\alpha$ monthly returns whereas volatility represents the average deviation or the return. Therefore, parametric assumptions on the return are indifferent from each other. Second, nice probabilistic assumptions on asset return must lead to the strong mathematical relations to the volatility. In equation (1), we can easily see that volatility explains everything about VaR under normality. Due to these reasons, historical VaR is applied to the study.

MDD is more widely used in asset management especially in stock market. This risk measure is simply computed as the ratio of the maximum drawdown from the previous peak to the next trough. Formally we can calculate MDD as follows. Let asset value be $S$ and the maximum asset value $M_{t}$ at time $t$.

$$
M_{t}=\max _{t_{0} \leq u \leq t} S_{u}
$$

Then the drawdown ratio at each time, $D_{t}$ is defined.

$$
D_{t}=\left(S_{t}-M_{t}\right) / M_{t}
$$

Finally, maximum drawdown(MDD) can be computed as,

$$
M D D_{t}=\min _{t_{0} \leq u \leq t} D_{u}
$$

Note that MDD is can be interpreted as maximum cumulative loss. Since drawdowns are calculated in negative values or zeros, we compute minimum value of the drawdowns in equation (3). Furthermore, MDD captures different type of risk from $\mathrm{VaR}$ in that MDD is path dependent. VaR simply indicates single worst realized return while MDD may come from a series of negative returns. Theoretically speaking, large size of VaR does not necessarily lead to large MDD because one big negative return is realized in the process of positive returns. Conversely, if several consecutive small negative returns are observed, MDD could be large whereas VaR is small. In this reason MDD and VaR can be considered two distinct risk measures. 


\section{Empirical Method}

For empirical study, we employ quintile portfolio analysis. The data is collected from Fn Data Guide, a local financial data vendor. The dataset includes monthly market data of all stocks listed in KRX, the stock exchange in Korea, from 1990 to 2016 (324 months). The data also contain three Fama-French risk factors on market, value and size. The total number of stocks is 1,104. In the empirical studies, stocks are filtered in if stock-return data are all available in the estimation period. Specifically, at the end of each year, we constructed the dataset with stocks that have return data for the past 24 consecutive months, and used the data for the estimation.

In this paper, the effects of risk measures on stock returns are examined in two steps. The first step is the quintile portfolio analysis with respect to volatility, VaR and MDD. In the second step, I construct 3-by-3 portfolios using two-way analysis depending on both volatility and VaR or MDD. In order to ensure that each portfolio contains a similar number of stocks, I first divide the stocks into three groups, in terms of volatility, and then construct three portfolios regarding VaR or MDD within each volatility group. The process is repeated at the end of each year with the estimation period of 24 months. In summary, the first step shows the unconditional effect of three risk measures, whereas the second step investigates the effect of VaR and MDD after conditioning volatility levels. In order to see the risk adjusted performances of each portfolio, Fama-French three factor model (Fama \& French, 1993) is employed.

\section{RESULT}

Table 1 reports the result of one way analysis. Panel A is for portfolios on volatility, panel 2 is for VaR and panel 3 is for MDD. The results are arranged in order of risk level, i.e. VOL1 is the portfolio constructed on the lowest volatility and VOL5 is the largest. The average returns, volatility and VaR are all in monthly terms.

Table 1. One-way Analysis

\begin{tabular}{l|r|r|r|r|r}
\hline Panel A & VOL1 & VOL2 & VOL3 & VOL4 & VOL5 \\
\hline Average & $1.63 \%$ & $2.07 \%$ & $1.95 \%$ & $1.64 \%$ & $1.34 \%$ \\
\hline Volatility & $8.08 \%$ & $9.56 \%$ & $10.22 \%$ & $10.89 \%$ & $11.63 \%$ \\
\hline VaR (5\%) & $-10.05 \%$ & $-10.48 \%$ & $-12.45 \%$ & $-13.29 \%$ & $-16.05 \%$ \\
\hline MDD & $-71.14 \%$ & $-75.63 \%$ & $-77.45 \%$ & $-81.28 \%$ & $-80.75 \%$ \\
\hline
\end{tabular}

\begin{tabular}{l|c|c|c|c|c}
\hline Panel B & VaR1 & VaR2 & VaR3 & VaR4 & \multicolumn{1}{c}{ VaR5 } \\
\hline Average & $1.56 \%$ & $1.72 \%$ & $1.89 \%$ & $1.90 \%$ & $1.56 \%$ \\
\hline Volatility & $7.96 \%$ & $8.99 \%$ & $9.69 \%$ & $10.84 \%$ & $13.55 \%$ \\
\hline VaR (5\%) & $-9.81 \%$ & $-10.36 \%$ & $-11.40 \%$ & $-12.87 \%$ & $-15.21 \%$ \\
\hline MDD & $-74.40 \%$ & $-73.01 \%$ & $-75.93 \%$ & $-77.25 \%$ & $-84.90 \%$ \\
\hline
\end{tabular}

\begin{tabular}{l|r|r|r|r|r}
\hline Panel C & MDD1 & MDD2 & MDD3 & MDD4 & MDD5 \\
\hline Average & $1.42 \%$ & $1.80 \%$ & $1.77 \%$ & $2.08 \%$ & $1.59 \%$ \\
\hline Volatility & $7.80 \%$ & $8.98 \%$ & $9.68 \%$ & $11.08 \%$ & $14.17 \%$ \\
\hline VaR (5\%) & $-9.83 \%$ & $-10.44 \%$ & $-11.41 \%$ & $-12.94 \%$ & $-15.84 \%$ \\
\hline MDD & $-71.21 \%$ & $-75.01 \%$ & $-77.30 \%$ & $-77.38 \%$ & $-83.65 \%$ \\
\hline
\end{tabular}

The average returns are bell shaped in cases of volatility and VaR, which is consistent with previous literature. The results from MDD portfolio do not show any patterns. The ex post risks of the portfolios in all measures increase along with previous risk level. It is interesting to observe that portfolios constructed with respect to one specific risk measure performs very similar to the ones that are constructed based on the other risk measures.

Next, the risk adjusted returns are computed in terms of Fama-French three factor model. Table 2 presents the result as blow. In the estimates, ${ }^{*}$ and $* *$ indicate $5 \%$ and $1 \%$ significant level. 
Table 2. Three Factor Model Evaluation

\begin{tabular}{|c|c|c|c|c|c|}
\hline \multicolumn{6}{|l|}{ Panel A } \\
\hline & VOL1 & VOL2 & VOL3 & VOL4 & VOL5 \\
\hline Intercept & 0.337 & 0.539 & 0.384 & $0.045^{* *}$ & $-0.243^{*}$ \\
\hline Market & $0.853^{* *}$ & $1.034^{* *}$ & $1.086^{* *}$ & $1.097^{* *}$ & $1.069^{* *}$ \\
\hline SMB & $0.454^{* *}$ & $0.555^{* *}$ & $0.654^{* *}$ & $0.767^{* *}$ & $0.818^{* *}$ \\
\hline HML & $0.356^{* *}$ & $0.413^{* *}$ & $0.366^{* *}$ & $0.316^{* *}$ & $0.286^{* *}$ \\
\hline \multicolumn{6}{|l|}{ Panel B } \\
\hline & VaR1 & VaR2 & VaR3 & VaR4 & VaR5 \\
\hline Intercept & 0.323 & 0.311 & $0.398^{*}$ & 0.293 & -0.274 \\
\hline Market & $0.836^{* *}$ & $0.970^{* *}$ & $1.054^{* *}$ & $1.158^{* *}$ & $1.125^{* *}$ \\
\hline SMB & $0.436^{* *}$ & $0.522^{* *}$ & $0.599^{* *}$ & $0.726^{* *}$ & $0.971^{* *}$ \\
\hline HML & $0.337^{* *}$ & $0.376^{* *}$ & $0.344^{* *}$ & $0.291^{* *}$ & $0.400^{* *}$ \\
\hline \multicolumn{6}{|l|}{ Panel C } \\
\hline & MDD1 & MDD2 & MDD3 & MDD4 & MDD5 \\
\hline Intercept & 0.300 & $0.446^{*}$ & 0.249 & $0.350^{*}$ & -0.301 \\
\hline Market & $0.829^{* *}$ & $0.980^{* *}$ & $1.048^{* *}$ & $1.140^{* *}$ & $1.149^{* *}$ \\
\hline SMB & $0.445^{* *}$ & $0.548^{* *}$ & $0.608^{* *}$ & $0.728^{* *}$ & $0.930^{* *}$ \\
\hline HML & $0.227^{* *}$ & $0.301^{* *}$ & $0.380^{* *}$ & $0.425^{* *}$ & $0.428^{* *}$ \\
\hline
\end{tabular}

All the factor exposures are significant under $1 \%$ level, while the intercept, or risk adjusted returns are mostly statistically insignificant. Therefore, risk measures may not predict future risk adjusted returns. Market exposures are bell shaped in volatility and VaR measures. MDD do not show any consistent patterns. We can see that the bell shaped pattern of raw returns in table 1 is from market risk. Another interesting observation is the SMB coefficients. The exposure to SBM is positively related to all three risk levels, which implies that small size leads to high volatility, $\mathrm{VaR}$ and MDD. On HML, the portfolios with three measures behave differently. MDD is positively related to HML while volatility is asymmetrically related. We cannot find any interesting patterns in case of VaR.

Table 3 and table 4 present two-way portfolio analysis. As explained in the previous section, stocks are divided into three groups in terms of volatility. Then, three portfolios based on the other risk measure are constructed within each volatility group, which results in nine portfolios. This analysis is independently conducted with VaR and MDD in the second step. 
Table 3. Two-Way Analysis with Volatility and VaR

\begin{tabular}{|c|c|c|c|}
\hline \multicolumn{4}{|c|}{ Panel A: Low Volatility } \\
\hline & Low VaR & Mid VaR & High VaR \\
\hline Average & $1.78 \%$ & $1.70 \%$ & $1.86 \%$ \\
\hline Volatility & $9.22 \%$ & $8.65 \%$ & $10.06 \%$ \\
\hline $\operatorname{VaR}(5 \%)$ & $-10.82 \%$ & $-10.89 \%$ & $-10.89 \%$ \\
\hline MDD & $-76.17 \%$ & $-76.50 \%$ & $-76.14 \%$ \\
\hline \multicolumn{4}{|c|}{ Panel B: Mid Volatility } \\
\hline & Low VaR & Mid VaR & High VaR \\
\hline Average & $2.13 \%$ & $2.11 \%$ & $2.15 \%$ \\
\hline Volatility & $10.90 \%$ & $10.15 \%$ & $12.02 \%$ \\
\hline $\operatorname{VaR}(5 \%)$ & $-13.31 \%$ & $-12.08 \%$ & $-14.92 \%$ \\
\hline MDD & $-77.45 \%$ & $-74.67 \%$ & $-80.13 \%$ \\
\hline \multicolumn{4}{|c|}{ Panel B: High Volatility } \\
\hline & Low VaR & Mid VaR & High VaR \\
\hline Average & $1.36 \%$ & $1.54 \%$ & $1.17 \%$ \\
\hline Volatility & $12.75 \%$ & $11.47 \%$ & $14.94 \%$ \\
\hline $\operatorname{VaR}(5 \%)$ & $-15.26 \%$ & $-16.47 \%$ & $-16.71 \%$ \\
\hline MDD & $-83.63 \%$ & $-79.51 \%$ & $-87.91 \%$ \\
\hline
\end{tabular}

Ex post risk performance are mainly explained by volatility. All the levels of volatility, VaR and MDD are greater when the volatility is higher. On the other hand, in each panel, i.e. with similar level of volatility, ex post risks do not show any consistent behavior. Even VaR, which is used for portfolio construction in the second step, do not predict future VaR.

The similar results are shown in table 4 in case of MDD. All three risk measures differ from each other in the direction of volatility levels. However, any significant difference cannot be found within the same group of volatility.

Table 4. Two-Way Analysis with Volatility and MDD

\begin{tabular}{|c|c|c|c|}
\hline \multicolumn{4}{|c|}{ Panel A: Low Volatility } \\
\hline & Low MDD & Mid MDD & High MDD \\
\hline Average & $1.88 \%$ & $1.85 \%$ & $1.91 \%$ \\
\hline Volatility & $9.43 \%$ & $8.63 \%$ & $10.67 \%$ \\
\hline $\operatorname{VaR}(5 \%)$ & $-10.76 \%$ & $-10.97 \%$ & $-11.75 \%$ \\
\hline MDD & $-76.50 \%$ & $-74.19 \%$ & $-79.99 \%$ \\
\hline \multicolumn{4}{|c|}{ Panel B: Mid Volatility } \\
\hline & Low MDD & Mid MDD & High MDD \\
\hline Average & $2.02 \%$ & $1.82 \%$ & $2.23 \%$ \\
\hline Volatility & $11.02 \%$ & $9.78 \%$ & $12.87 \%$ \\
\hline $\operatorname{VaR}(5 \%)$ & $-12.78 \%$ & $-12.58 \%$ & $-17.07 \%$ \\
\hline MDD & $-78.86 \%$ & $-75.82 \%$ & $-82.15 \%$ \\
\hline \multicolumn{4}{|c|}{ Panel B: High Volatility } \\
\hline & Low MDD & Mid MDD & High MDD \\
\hline Average & $1.35 \%$ & $1.23 \%$ & $1.37 \%$ \\
\hline Volatility & $11.74 \%$ & $10.25 \%$ & $12.26 \%$ \\
\hline $\operatorname{VaR}(5 \%)$ & $-15.22 \%$ & $-15.74 \%$ & $-15.25 \%$ \\
\hline MDD & $-81.84 \%$ & $-81.50 \%$ & $-83.18 \%$ \\
\hline
\end{tabular}




\section{CONCLUSION}

Measuring risk has been believed an important factor in asset management. Although volatility is the most popular risk measure, many researchers and practitioners propose alternative measures such as VaR and MDD. This article tries to find out whether these alternative measures contain any additional information to volatility in individual stocks.

Using Korean stocks, this paper shows empirical results based on portfolio analysis. Basically two types of experiments are conducted: one-way, i.e. unconditional analysis, and two-way analysis, or conditional analysis on volatility. Both empirical studies tell us the same result; VaR and MDD do not capture any additional information to volatility.

Specifically, all the risk measures predict the level of three kinds of ex post risks. High risk results in high ex post risks including controlling risk itself and other risks. Nonetheless, if one controls volatility level, VaR and MDD do not capture the other types of risks. Combining these two results, we may conclude that VaR or MDD do not contain any additional risk other than volatility in stock market.

\section{AUTHOR BIOGRAPHY}

Soo-Hyun Kim is currently at Soongsil University as an Assistant Professor of Finance. Prior to Soongsil University he worked for Samsung Asset Management as a quantitative investment strategist. Mailing Address: 369 Sangdoro, Seoul, South Korea. Email: soo_hyun.kim@ssu.ac.kr

\section{REFERENCES}

Adrian, T., \& Rosenberg, J. (2008). Stock returns and volatility: Pricing the short-run and long-run components of market risk. The Journal of Finance, 63(6), 2997-3030.

Ang, A., Hodrick, R. J., Xing, Y., \& Zhang, X. (2006). The cross-section of volatility and expected returns. The Journal of Finance, 61(1), 259-299.

Ang, A., Hodrick, R. J., Xing, Y., \& Zhang, X. (2009). High idiosyncratic volatility and low returns: International and further US evidence. Journal of Financial Economics, 91(1), 1-23.

Douady, R., Shiryaev, A. N., \& Yor, M. (2000). On probability characteristics of" downfalls" in a standard Brownian motion. Theory of Probability \& Its Applications, 44(1), 29-38.

Duffie, D., \& Pan, J. (1997). An overview of value at risk. The Journal of derivatives, 4(3), 7-49.

Fama, E. F., \& French, K. R. (1993). Common risk factors in the returns on stocks and bonds. Journal of Financial Economics, 33(1), 3-56.

Giot, P., \& Laurent, S. (2003). Market risk in commodity markets: a VaR approach. Energy Economics, 25(5), 435-457.

Huang, Y. C., \& Lin, B. J. (2004). Value-at-risk analysis for Taiwan stock index futures: Fat tails and conditional asymmetries in return innovations. Review of Quantitative Finance and Accounting, 22(2), 79-95.

Kang, S. H., \& Yoon, S. M. (2007). Value-at-Risk Analysis of the long memory volatility process: The case of individual stock returns. Asian Review of Financial Research, 21(1), 101-130.

Kim, D. (2011). Relevance of maximum drawdown in the investment fund selection problem when utility is nonadditive. Journal of Economic Research, 16(3), 257-289.

Kim, T., \& Lee, H. (2011). Comparative analysis results on the maximum drawdown, Calmar ratio in the global and Korean stock market. Journal of Industrial Economics and Business, 24(4), 1989-2009.

Magdon-Ismail, M., Atiya, A. F., Pratap, A., \& Abu-Mostafa, Y. S. (2004). On the maximum drawdown of a Brownian motion. Journal of Applied Probability, 41(1), 147-161.

Wu, P. T., \& Shieh, S. J. (2007). Value-at-Risk analysis for long-term interest rate futures: Fat-tail and long memory in return innovations. Journal of Empirical Finance, 14(2), 248-259. 